\title{
Information Needs of Public Health Staff in a Knowledge Translation Setting in Canada ${ }^{1}$
}

\author{
Mê-Linh Lê
}

\begin{abstract}
Introduction: In response to emerging public health crises in the early 2000s, the Government of Canada recognized the need for a more coordinated public health approach and launched the six National Collaborating Centres for Public Health (NCCPH). The information needs and information-seeking behavior of public health professionals is a relatively understudied area. In this paper, the results of a survey of NCCPH staff is provided and discussed as a means to help fill this gap in the literature. Also examined is the use of information specialists to ascertain whether they are being used to their full potential. Methods: A combination of telephone interviews, a literature review, and a questionnaire distributed to relevant staff. Results: The results indicated some similarities with previous studies such as a reliance on journal articles and colleagues as information sources. It was also shown that staff is unaware of many information resources now available. Training was indicated as a potential area of skills-based growth, as most staff have received limited instruction on searching and information retrieval skills, and required competencies can change frequently as new services, tools, and databases are introduced. Discussion: There is a strong inclination from the staff surveyed to seek information on their own, without the use of an information specialist. However, respondents indicated they are challenged most in their information seeking by a lack of time and awareness of what resources are available, two knowledge areas for which an information specialist is uniquely qualified. Awareness must be raised of the specialized skills of information specialists and how they are able to assist in the information-seeking and retrieval process.
\end{abstract}

\section{Introduction}

The healthcare system in Canada is undergoing constant change and nowhere is this more evident than in the increased awareness and discussion around public health $(\mathrm{PH})$ issues (e.g., SARS, Waterton, pH1N1, etc.). Therefore, it is becoming increasingly important, that $\mathrm{PH}$ workers and policy makers involved in any form of decision making have access to the best evidence available and that it is in a format that can be quickly and easily understood. The demand for this type of evidence and knowledge translation (KT) products led to the creation of the Canadian National Collaborating Centres for Public Health (NCCPH, http://nccph.ca/). Relatively few studies have been done on the information needs of PH professionals, and none at all were found that focused on individuals involved in KT. Individuals practicing KT have different information needs than practicing clinicians, academics, or front-line health professionals - professions on which the majority of information needs scholarship has focused. Specifically, PH workers involved in KT need access to high-quality evidence-based information that ideally includes in-depth methodology discussions (e.g., sample size, sampling techniques) both to allow for comparisons with other studies and to allow the $\mathrm{PH}$ worker to judge the overall strength of the study. ${ }^{3}$

To help address the gap in knowledge regarding the information needs of $\mathrm{PH}$ professionals, this study examines the information needs of a small group of $\mathrm{PH}$ professionals involved in a KT setting and seeks to address whether their information needs are being met; what types of information sources are being used; what forms of training are provided; the confidence of workers in their ability to find, access, and appraise information; and how staff currently use an information specialist. ${ }^{4}$

\footnotetext{
${ }^{3}$ See Health-Evidence.ca for examples of high-quality $\mathrm{PH}$ research that has been critically appraised for its methodological rigour.

${ }^{4}$ Each NCC differs in how they refer to a person in this role, typically using either the term "information specialist" or "librarian". To lessen confusion, only information specialist will be used in this paper when referring to the NCCs but it is acknowledged that for all intents and purposes the two terms are interchangeable and are meant to indicate an individual with a MLS, MLIS, or similar degree.
}

Mê-Linh Lề․ Liaison Librarian, Health Sciences Library, University of Saskatchewan, 107 Wiggins Rd, Saskatoon, SK S7N 5E5.

${ }^{1}$ This paper is peer reviewed.

${ }^{2}$ Corresponding author (e-mail: me-linh.le@usask.ca). 
The National Collaborating Centres for Public Health

In the early 2000s a number of PH crises emerged in Canada and internationally (e.g., SARS). The Government of Canada, recognizing that more effort was needed to coordinate the dissemination of information and to strengthen their PH response, conducted a comprehensive literature review and interviewed numerous international $\mathrm{PH}$ organizations and individuals on how best to support research into $\mathrm{PH}$ and coordinate knowledge translation activities [1]. In 2004 and 2005, as a result of the findings and recommendations, six National Collaborating Centres (NCCs) for Public Health were created (Table 1). The Centres are spread geographically across Canada, and while each Centre has a federal mandate and all centres collaborate on certain projects, their primary foci are different and each concentrates on a specialized area of $\mathrm{PH}$ [2].

When created, each NCC conducted an individual environmental scan of experts in their specific area of PH. This helped to identify knowledge gaps and the information needs that were not currently being met. Using the results of their scan as a basis, but including other inputs (e.g., suggestions from $\mathrm{PH}$ workers, requests from government officials) each Centre synthesizes the best available scientific evidence into a variety of formats such as evidence reviews, white papers, systematic reviews, knowledge tools, and conference presentations. Medlar et al. [2] outlined the impact these activities are intended to have, including:

- increasing effectiveness of PH programs and policies;

- facilitating the exchange of knowledge between experts and practitioners in $\mathrm{PH}$; and

- ensuring that this knowledge is more widely available for use by PH policy makers, program managers, and practitioners.
A large component of the NCC mandate is ensuring that expert knowledge on $\mathrm{PH}$ topics is "translated" for $\mathrm{PH}$ professionals and policy makers. This requires that the NCCs use high-quality evidence found primarily through searching the scholarly or grey literature in their work.

The staff of each Centre includes a Scientific Director, project managers, scientists, educators, and communication specialists. Each Centre differs in its access to and use of an information specialist (Table 2).

As the former Information Specialist at one of the Centres, this work grew out of the realization that each NCC has differing levels of access to scientific evidence and that staff members have varying skill levels in terms of information retrieval. As will be discussed, $\mathrm{PH}$ information can be difficult to locate and many of the topic areas have little information formally published on them.

\section{Literature review}

$\mathrm{PH}$ is concerned with the promotion, protection, improvement, and restoration of the health of an individual, group, or population [3]. In Canada the PH system aims to protect Canadians from injury and disease and to help them stay healthy [4]. Studying the information needs of PH workers has always been complicated because the field is comprised of a diverse group of professionals including doctors, nurses, epidemiologists, inspectors, nutritionists, veterinarians, toxicologists, dentists, biostatisticians, social workers, environmental scientists, and more [5]. PH information is also notoriously difficult to locate and (or) retrieve. Owing to the nature of $\mathrm{PH}$ research, which includes a number of subject areas (e.g., health sciences, engineering, public policy, etc.), the literature is scattered across numerous domains [6, 7]. It is not surprising, therefore, that the varied nature of $\mathrm{PH}$

Table 1. The National Collaborating Centres for Public Health.

\begin{tabular}{lll}
\hline Centre & Location & Host Organization \\
\hline NCC for Aboriginal Health & Prince George, BC & University of Northern British Columbia (UNBC) \\
NCC for Environmental Health & Vancouver, BC & British Columbia Centre for Disease Control (BCCDC) \\
NCC for Infectious Diseases & Winnipeg, MB & International Centre for Infectious Diseases (ICID) \\
NCC for Methods and Tools & Hamilton, ON & McMaster University \\
NCC for Healthy Public Policy & Montreal, QC & Institut national de santé publique du Québec (INSPQ) \\
NCC for Determinants of Health & Antigonish, NS & St. Francis Xavier University \\
\hline
\end{tabular}

Table 2. Access to Information Specialists and Library Resources.

\begin{tabular}{|c|c|}
\hline $\mathrm{H}$ & Affiliation with UNBC allows staff to access UNBC library resources and training sessions \\
\hline NCCEH & $\begin{array}{l}\text { Has one information specialist as a full-time staff member; access to Library resources through variety of means (e.g., some } \\
\text { staff are adjunct professors at universities; BC has a provincial health library consortium (eHLBC)) }\end{array}$ \\
\hline NCCID & $\begin{array}{l}\text { No formalized access to library resources or an information specialist; informal relationship with the information specialist } \\
\text { at the National Microbiology Laboratory }\end{array}$ \\
\hline NCCMT & $\begin{array}{l}\text { Provides staff access to two information specialists (MLIS and PhD) and one library technician on a cost-recovery basis; } \\
\text { affiliation with McMaster University allows users access to library resources }\end{array}$ \\
\hline NCCHPP & $\begin{array}{l}\text { Host institution offer access to librarian and training sessions; NCCHPP subscribes to several full-text online databases } \\
\text { (e.g., Medline, SocioIndex, Sociological Abstracts, Political Abstract) }\end{array}$ \\
\hline $\mathrm{NCCDH}$ & $\begin{array}{l}\text { At the time of writing was in the process of hiring an information specialist; affiliation with St. Francis Xavier University } \\
\text { allows users access to library resources }\end{array}$ \\
\hline
\end{tabular}


work and the variety of job functions [8] have made it difficult to accurately describe the information needs of $\mathrm{PH}$ professionals [9-12]. Attempts have been made, however, especially during the last 20 years, to better understand the information needs of this unique and diverse workforce.

One study documented the reorganization of a Teaching Public Health Unit in Ontario, which led to an increase in journal subscriptions, the hiring of library staff, and regular MEDLINE training sessions and library orientations [13]. Other early research examined access to online resources by $\mathrm{PH}$ workers and found that limited access to a computer or the internet was a barrier $[14,15]$.

Rambo examined a number of issues for PH workers in Washington and noted several findings including the identification of key resources [7] and the needs of practitioners; specifically better tools, more outcome measures and best practices, standardized templates, and evidence summaries [16]. These findings are echoed in subsequent information needs interviews along with additional identified needs such as the call for improved access to grey literature, better methods for limiting searches, and effective archiving methods for relevant information [10].

Semi-structured interviews with $28 \mathrm{PH}$ practitioners in Washington analyzed the information needs relating to immunization data [9]. Focus groups with other Washington-area health jurisdictions found an incredible amount of diversity in both the workforce and in the information needs [17]. Pham's examination of the selfidentified information needs of public health food inspectors (PHIs) found that PHIs are confident in their general knowledge of PH topics, but a central online resource was needed [18]. A training needs survey of PH workers also found that on-site training is the preferred model for receiving instruction [19].

The use of evidence-based practice is not as widespread in $\mathrm{PH}$ as it is in other health professional fields. A qualitative study in Norway, for instance, explored this topic and found that using evidence was not common among PH practitioners even though the study authors identified the potential for greater use of research in $\mathrm{PH}$ practice [20]. Possible reasons for a lack of uptake include psychological barriers (e.g., lack of awareness of resources), environmental barriers (e.g., policy makers might not see research-based information as important), and potential differences in source characteristics (e.g., accessibility) [21]. More recent work by Canadian researchers identified a number of key resources, which were then mapped to the Six-S evidence pyramid, relevant to $\mathrm{PH}$ workers involved in evidence-based practice [22].

A comprehensive literature review on the information needs of PH professionals in 2007 found that the underlying message from previous studies all showed a need for trustworthy, high-quality, authoritative, verifiable, current, convenient, and accessible information. Barriers to accessing information included time, reliability, credibility, and information overload [23]. The need for a central repository for $\mathrm{PH}$ information has also been identified in the literature $[10,16,17,24,25]$. Attempts have been made to rectify the need for a central repository [26, 27], and while these projects have undoubtedly been helpful, they have not been able to fill the gap completely.
Owing in no small part to the complexity and dispersal of $\mathrm{PH}$ information, locating it requires expert searching skills [24]. A preponderance of Medical Subject Headings (MeSH) not specific enough for PH queries, the absence of randomized controlled trials (often deemed inappropriate in PH scenarios [28]), a lack of standard terminology, relevant journals not indexed in MEDLINE, Englishlanguage biases, and high usage of grey literature all add to this complexity $[6,11,24]$. Hand searching of journals is one way to increase the number of relevant results in a $\mathrm{PH}$ literature search [29]. A further complication is the desire of librarians to offer PH workers what is known and familiar (e.g., clinical or knowledge-based information) even though population-based information (e.g., disease incidence data, vaccination guidelines) may be more useful [30].

Finally, reviews of the literature highlight the need for information-needs studies of different segments within the PH workforce, $[23,30]$. While there have been studies addressing the needs of $\mathrm{PH}$ practitioners $[15,20]$, inspectors [18], nurses [31], and university faculty [32] there have yet to be any examining those involved in $\mathrm{PH}$ knowledge translation. This study seeks to address that gap.

\section{Knowledge translation}

As mentioned previously, one of the critical activities of the NCCs is to "translate relevant evidence produced by academics and researchers so that it can be used by $\mathrm{PH}$ practitioners and policy-makers." [33]. Over the last few years there has been much written on the use of knowledge translation and its related concepts knowledge synthesis, management, exchange, brokerage, and transfer ${ }^{5}$ as a means to more rapidly turn research into practice, particularly in the health care world [34-39]. This paper applies the KT definition put forth by the Canadian Institutes for Health Research (CIHR), which defines it as a "dynamic and iterative process that includes synthesis, dissemination, exchange, and ethically sound application of knowledge." The NCC websites list a number of their PH KT products and include examples such as evidence reviews on social distancing as a preventative measure during pandemics [40], workshops for front-line PH workers on the threats and challenges associated with radon exposure, [41] and fact sheets on the importance of disaggregated data when conducting research with Aboriginal populations [42].

\section{Methods}

\section{Study design}

The following study consisted of: (i) telephone interviews with the Scientific Directors of each NCC (or a designate), and (ii) an online survey distributed to all NCC staff members involved in searching for information. After being granted ethics exemption, semi-structured phone interviews were conducted with five of the Scientific Directors (or designates) between January and April 2011. (It was not possible to obtain an interview with

\footnotetext{
${ }^{5}$ For an in-depth discussion on the use and misuse of KT terminology over the years, see Graham et al. [34].
} 
one of the Scientific Directors). The interviews ranged from 30 to 90 minutes and consisted of 17 open-ended questions focusing on the type of projects that the particular NCC works on, the process for identifying research topics, access to an information specialist and information resources, training or procedures related to searching for evidence, critical appraisal tools present or used, access to bibliographic management software, and satisfaction with current access to information resources. The answers to each question were transcribed by the author and inserted into an Excel spreadsheet. The interviews served the dual purpose of providing background information on how each NCC completes its research process and helping inform the creation of questions for the survey.

The online survey was created using FluidSurveys and distributed via email to staff for four weeks between April and May 2011 (the survey is available at https://sites.google. com/site/nccinfoneeds/). Because of the geographic distribution and number of participants, a web-based survey was chosen as the most appropriate way to reach participants. An invitation email with a link to the survey was sent to a contact person at each NCC who then distributed it to the staff. A reminder email was sent towards the end of the survey period, again inviting the NCC staff to participate. A one in four chance to win a $\$ 25$ gift card to a national book chain was offered as an incentive to participate. The survey was a mix of closed and open-ended questions. Questions were created using the information gleaned from the telephone interviews and through prior studies on information needs $[43,44]$. The survey consisted of:

- ten demographic questions,

- eight questions on information resources,

- five questions on training and education related to searching for information,

- three questions on evaluating information,

- seven questions on access to information,

- three questions on the challenges associated with finding information, and

- two questions on future needs.

\section{Results}

The survey was designed to be completed by all NCC staff; a question on the first page of the survey differentiated between those who searched for information in their day-to-day work (e.g., knowledge translation scientists) and those who did not (e.g., administrative staff). The latter were directed to the final page and thanked for their participation while the former were able to complete the survey in full. However, as a single contact person at each NCC distributed the survey, it soon became clear that the survey was only being distributed to people that the contact person deemed relevant. While this may appear to be a limitation of the study, it is the belief of the author that because the contact person (usually the Scientific Director or Centre Manager) had a solid understanding of the project as a result of the phone interview, they would therefore have a good understanding of whom the survey applied to and would have forwarded it on to the appropriate individuals.

In total there were 18 respondents out of a pool of 23 , for a response rate of $78.26 \%$. It should be noted that these 18 respondents were all from five NCCs. Staff from the National Collaborating Centre for Healthy Public Policy (NCCHPP) were not able to participate as is discussed in the Limitations.

\section{Demographics}

The number of responses received from the five NCCs ranged from one to six responses per NCC (average response 3.6). Of these, $94 \%(n=17)$ were women, with an age range predominantly between 25 and $34(n=7$; $39 \%$ ). Previous studies have indicated that many $\mathrm{PH}$ workers do not have a specific $\mathrm{PH}$ background or advanced degree [45], a finding not echoed at the NCCs where the large majority hold at least a Master's level degree and $27 \%(n=5)$ hold a PhD or MD. Most respondents are full-time staff $(n=15 ; 83 \%)$ who have worked for an NCC for over 2 years $(n=8 ; 44 \%)$. Additionally, 56\% $(n=10)$ have worked in $\mathrm{PH}$ for $2-5$ years with $22 \%(n=4)$ working in $\mathrm{PH}$ for over 20 years.

At the end of the demographics portion of the survey, respondents were asked to indicate whether they searched for information in their day-to-day work. Those who did not $(n=3 ; 17 \%)$ were sent to the end of the survey. As such, the following data include responses that were collected from only fifteen respondents unless otherwise noted in the sections on Information Challenges and Access to An Information Specialist.

\section{Information resources}

When searching for information it was found that $93 \%$ of respondents $(n=14)$ prefer searching themselves, $80 \%$ ( $n=12$ ) ask for assistance from an information specialist, and $60 \%(n=9)$ contact a colleague. When starting a search for information, respondents were most likely to visit a library website $(n=10 ; 67 \%)$ or a journal database ( $n=10 ; 67 \%)$. A web search engine such as Google or Bing was the third most popular resource, with $47 \%$ $(n=7)$ indicating they were very likely to go there when starting a project. Colleagues and federated search engines were indicated as very likely sources by $33 \%(n=5)$, while HealthEvidence.ca and the Trip Database were unlikely to be used as starting resources.

In terms of resource type, journal articles $(n=15 ; 100 \%)$, online searches $(n=11 ; 73 \%)$, reports and government reports $(n=9 ; 60 \%)$, and colleagues $(n=9 ; 60 \%)$ were chosen as resources most frequently used. Books or book chapters $(n=10 ; 67 \%)$, statistics $(n=10 ; 67 \%)$, and conference presentations $(n=8 ; 53 \%)$ were used only occasionally, while websites such as TRIP $(n=6 ; 43 \%)$, popular media $(n=7 ; 47 \%)$, newsletters $(n=5 ; 33 \%)$, and conference proceedings $(n=9 ; 60 \%)$ were used infrequently.

Specific resources identified as being used frequently were Google $(n=10 ; 67 \%)$, PubMed $(n=10 ; 67 \%)$, Medline $(n=9 ; 60 \%)$, EBSCO databases $(n=6 / 14 ; 43 \%)$, Google Scholar $(n=6 ; 40 \%)$, and OVID databases $(n=6 ; 40 \%)$. The Cochrane Library $(n=7 ; 47 \%)$ was used occasionally, while the databases Global Health, HealthEvidence.ca, and Web of Science were all used 
Fig. 1. Frequency of resource use.

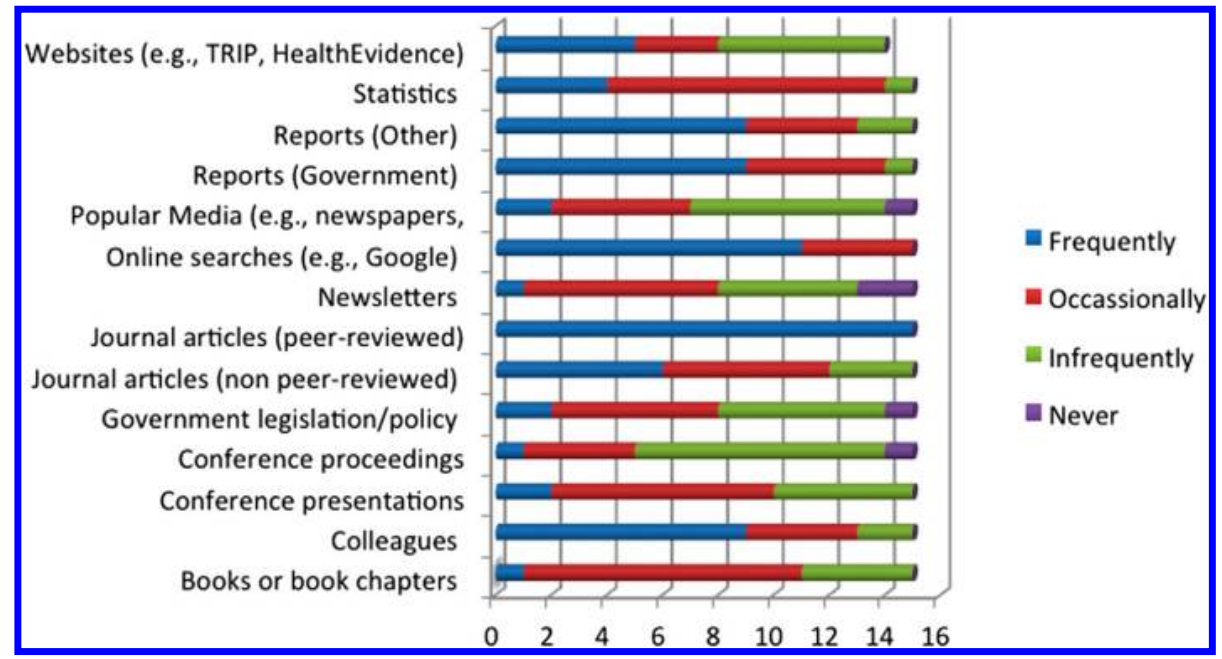

infrequently (Figure 1). Resources that the majority of the respondents had not even heard of include the Canadian Agency for Drugs and Technologies in Health (CADTH), Cumulative Index to Nursing and Allied Health Literature (CINAHL), HealthStar, MacPlus SF, Scopus/SciVerse, Centre for Reviews and Dissemination, and TRIP. Respondents were also asked to list specific resources that they used in their work. Not surprisingly, these tended to vary a great deal between participants and were much more specific to a particular topic area within $\mathrm{PH}$ (e.g., Bibliography of Native North Americans, GREENR Gale, etc.).

Popular tools used by respondents to keep up-to-date include conferences $(n=12 ; 80 \%)$, colleagues $(n=11$; $73 \%)$, listservs $(n=9 ; 60 \%)$, newsletters $(n=8 ; 53 \%)$, and popular media $(n=8 ; 53 \%)$. Popular social media tools such as RSS, blogs, Facebook, and table of content alerts are not used frequently.

Respondents were asked about the type of searcher that they are and $53 \%(n=8)$ indicated that they considered themselves effective searchers, while $40 \%(n=6)$ identified as efficient searchers, and $33 \%(n=5)$ were neutral on their efficiency and efficacy as a searcher, while $13 \%$ $(n=2)$ and $27 \%(n=4)$ did not feel that they were effective or efficient, respectively.

\section{Training}

When asked about their training on searching for and evaluating information, $67 \%(n=10)$ had attended classroom lectures or workshops, $33 \%(n=5)$ had access to handouts and guides, $33 \%(n=5)$ had taken university courses, and $27 \%(n=4)$ had received one-on-one instruction. Additionally, $47 \%(n=7)$ took advantage of other training resources such as journal clubs and group visits from information specialists. Frequency of training was poor; $7 \%(n=1)$ had received no training, $40 \%(n=$ 6 ) had received training only once, while $33 \%(n=5)$ were only trained 2-5 times. For future sessions, $87 \%(n=13)$ prefer training in a class setting, while $60 \%(n=9)$ prefer to teach themselves (Figure 2). Satisfaction levels with
Fig. 2. Preference for receiving training or instruction (more than one option could be selected).

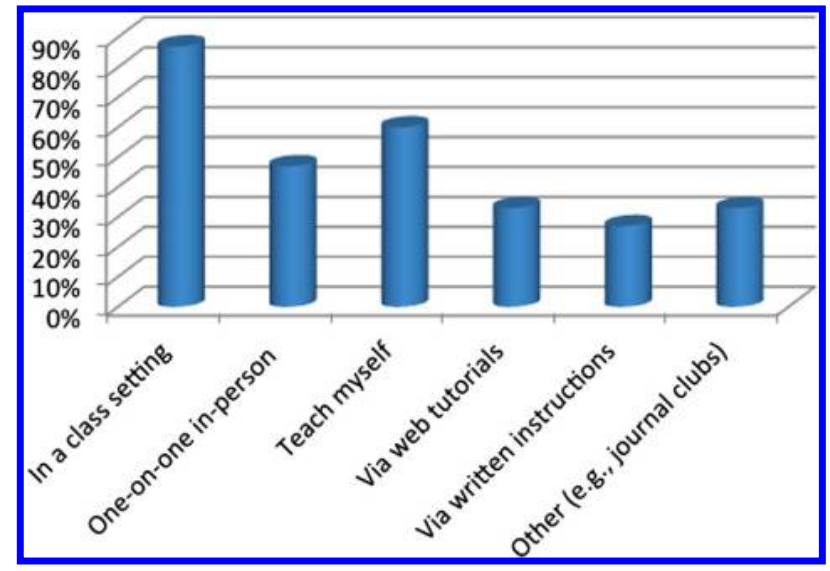

training indicated $40 \%(n=6)$ were satisfied or very satisfied, $27 \%(n=4)$ were unsatisfied or very unsatisfied, and $33 \%(n=5)$ responded that they were neutral.

\section{Time spent searching}

In terms of time spent searching for information every day, $47 \%(n=7)$ spent less than one hour, $33 \%(n=5)$ spent one to two hours, and $30 \%(n=3)$ spent more than three hours per day. When asked about time spent searching for each project $27 \%(n=4)$ indicated $0-5$ hours, $7 \%(n=1) 5-10$ hours, $20 \%(n=3) 15-20$ hours, and 7\% $(n=1)$ spent over 20 hours (It is possible this number is skewed slightly as it was also answered by information specialists, whose primary job is searching for information). The remaining respondents indicated that the time spent searching varied too greatly by project to quantify. On average, the majority of respondents will give up searching for information if they don't find what they are looking for after 15-20 minutes $(n=7 ; 47 \%)$, $1-2$ hours $(n=3 ; 20 \%)$, or over 2 hours $(n=3 ; 20 \%)$. 
Respondents indicated that if their search was unsuccessful they often try another searching method (e.g., asking a colleague or information specialist).

\section{Evaluating information}

Respondents ranked certain criteria from most to least important when evaluating information: accuracy of information and relevance were easily the most important; ease of use and access and comprehensiveness were moderately important; and timeliness, reputation of source, and price were not important. When asked about their satisfaction with their ability to critically appraise or evaluate information, $60 \%(n=9)$ responded that they were satisfied or very satisfied, while only $13 \%(n=2)$ were unsatisfied.

\section{Access to an information specialist}

It was found that $64 \%(n=9 / 14)$ have access to an information specialist, $14 \%(n=2 / 14)$ do not, and $21 \%$ $(n=3 / 14)$ were unsure. The large majority of those who have access tended to contact the information specialist while searching for information less than once a week $(n=7 / 10 ; 70 \%)$, while the remaining $30 \%(n=3 / 10)$ contacted them one to two times $(20 \%)$ or three to four times $(10 \%)$ a week (Figure 3). Accessing information can often be tricky, especially when it comes to journal articles requiring a subscription. This, however, does not appear to be a problem at the NCCs, as $60 \%(n=6 / 10)$ contacted an information specialist less than once a week on access issues, $20 \%(n=2 / 10)$ contacted them one to two times a week, and $10 \%(n=1 / 10)$ either once a week or never (Figure 4).

Fig. 3. How frequently an information specialist is consulted regarding searching for information.

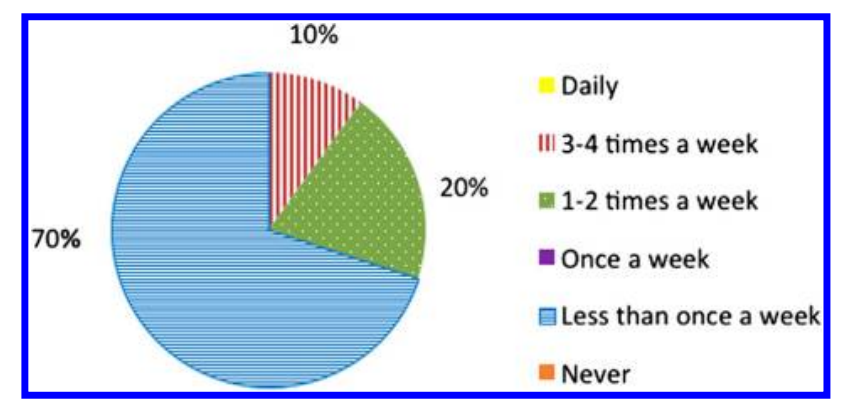

Fig. 4. How frequently an information specialist is consulted regarding accessing information.

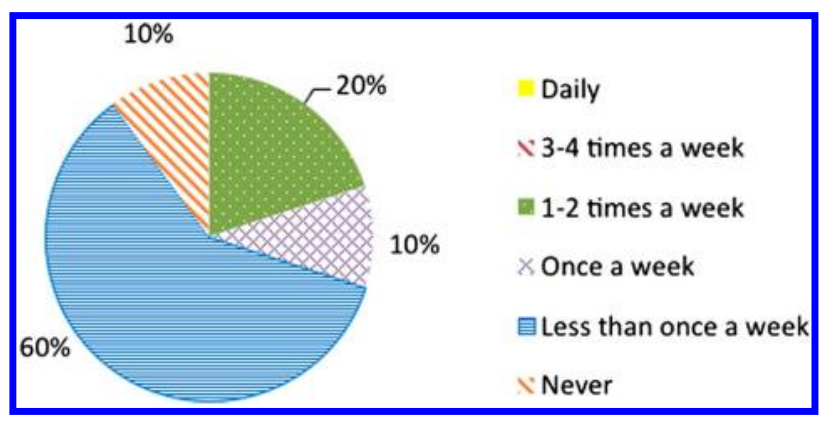

\section{Information challenges}

When indicating which tasks respondents found challenging, the majority responded that finding information (e.g., searching), accessing information (e.g., getting fulltext access), or knowing what information is available were tasks that were somewhat challenging. Knowing where to look for information and knowing what information is available were deemed not challenging. When asked which factors limit the use of information resources, time was the largest factor $(n=12 / 13 ; 92 \%)$, followed by lack of awareness of potential resources $(n=7 / 13 ; 54 \%)$, a lack of training $(n=4 / 13 ; 31 \%)$, and access issues $(n=2 / 13$; $15 \%$ ) (Figure 5). Staff also indicated that the sheer amount of information was overwhelming and help was needed to prioritize and to be systematic.

\section{Discussion}

This study examines the information needs and information-seeking behaviors of a select group of $\mathrm{PH}$ professionals involved in KT. Many of the findings agreed with previous research: a preference for journal articles [43] and on-site training [19], a desire to improve searching skills [14], and the need for high-quality and relevant $\mathrm{PH}$ information [23]. This study, however, also highlighted important considerations regarding the needs of $\mathrm{PH}$ workers that have not been noted previously.

Specifically, it is clear that awareness needs to be raised, both within the NCCs and the larger PH community, of various $\mathrm{PH}$ resources not being used. For example, while this study shows that traditional tools such as Medline, PubMed, Google, and Google Scholar are well used, other resources such as TRIP, HealthEvidence.ca, and Scopus are not well known. Other tools, such as the recently launched Canadian Best Practices Portal for Health Promotion and Chronic Disease Prevention would also likely be useful to NCC staff [46]. As PH information can be so difficult to locate, the more tools $\mathrm{PH}$ workers have at their disposal, the better.

NCC staff still preferred more traditional means of keeping up-to-date such as conferences, colleagues, and listservs. To save time and to cut travel costs, awareness must be raised as to the variety of free notification tools now available, such as RSS feeds, Table of Content alerts and Google news alerts. Once these types of feeds or alerts are established, they provide an ongoing and regular stream of updates related to an individual's particular area of focus and increase more timely awareness of developments in the field.

Fig. 5. Factors limiting the use of information resources.

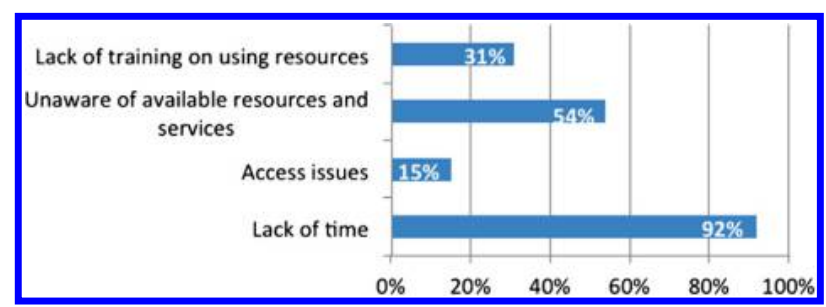


A further finding, which can also be broadly applied to information specialists working in all areas, is the need for a better understanding of information specialist skills and how they can aid researchers and other workers. Based on the usage statistics, it is clear that most staff at the NCCs are unaware of the resource they have at their fingertips the information specialist - who can save them both time and effort, and as a result of their expertise, is likely to increase the quality of evidence they are retrieving. For example, $86 \%$ of participants noted that they are comfortable searching for information themselves, suggesting that many are hesitant or unwilling to ask for assistance from an information specialist or do not have ready access to one. One way to increase or promote use of information specialists would be to create policies that either strongly recommended or make mandatory the use of an information specialist for appropriate projects similar to the use of information specialists in many systematic review and grant application teams. Educating staff on the many ways an information specialist can contribute to the information process may result in higher usage. This is particularly important because staff indicated that time and lack of awareness regarding resources available were their most significant barriers to accessing information resources; both of these are areas where information specialists or librarians are specifically trained and able to assist PH workers. Ultimately, a shift must be made in how librarians or information specialists are perceived and how their skills can be more broadly applied.

There is also an opportunity for the NCCs to expand their training efforts. Most have attended either one or no training sessions, indicating significant room for growth. In addition to traditional sessions (e.g., Medline), other potential sessions that may be valuable include the use of citation management programs, advanced searching in Google/Google Scholar, keeping up-to-date, and grey literature searching. Effective and efficient searching is a skill, and like other skills it needs to be refreshed with training at regular intervals. A large number of respondents specified that they prefer instruction in a classroom setting, meaning that the information specialist could reach several staff members at once. It is also possible that NCCPH could create its own online training videos or tutorials that could then be viewed by staff at any time, while also creating a standard search protocol. A desire for increased training is demonstrated as only $40 \%$ of staff consider themselves an efficient searcher - suggesting there is potential for skill development.

\section{Limitations}

It is recognized that the small sample size and specific nature of the NCCs limit the external validity and generalizability of the study findings. The small sample size is, in large part, a reflection of the small number of individuals working at the NCCs who search for and appraise evidence as part of their job. It is worth repeating here, that while the sample size is admittedly small, the response rate is quite high (78.26\%). Although the survey was distributed via a single contact person at each NCC as opposed to direct contact from the author to participant, the high response rate does show that the large majority of relevant individuals did complete the survey. This makes the findings of the study highly relevant to the NCCs to aid in their planning and training related to information retrieval and analysis. An additional limitation of this study is the lack of participation from NCCHPP. There are a variety of possible reasons for the lack of participation, including conflicting schedules, language barriers, or the focus area this NCC covers. Public policy literature is generally indexed in different databases than health or $\mathrm{PH}$ databases. Thus, this survey may not have been perceived as especially useful for this Centre. Also, the invitation email and survey were only available in English. While all NCHPP staff are bilingual, to be as inclusive as possible, future iterations of this study should ensure that all material is available in French as well.

\section{Future research directions}

It is hoped that this study will prompt further inquiries into the needs of $\mathrm{PH}$ professionals in Canada, with a particular focus on those using evidence in their decisionmaking process. Not only will this increase the external validity of this study, but it will also add to our understanding of an often-ignored health profession. In addition, $\mathrm{KT}$ is now a firmly established process, particularly in the health sciences, and has become a requirement for many health sciences grants and funding. This study has highlighted important information need considerations for $\mathrm{PH}$ workers involved in KT. To further this understanding of the differences in information needs facing researchers involved in $\mathrm{KT}$, as opposed to traditional researchers or clinicians, additional studies are needed.

It would also be worthwhile to more closely examine whether the low usage of an information specialist is seen in other PH organizations or environments. Examining why individuals are hesitant to use the skills of an information specialist has been well studied at the university level [47-50], but it would be instructive to learn whether library anxiety might transfer from a university environment to a professional one.

\section{Conclusion}

While the majority of these findings pertain to NCC staff, it is likely that many, particularly for preferences regarding information resources and keeping up-to-date, could be more broadly applied to $\mathrm{PH}$ workers of all types, whether they are front-line staff, researchers, or policy makers. These types of considerations could be useful when planning continuing education sessions at conferences, information literacy sessions in $\mathrm{PH}$ organizations, or various other venues.

Ultimately, it is hoped that this study contributes to the growing body of literature around the information needs of PH workers, particularly those involved in knowledge translation. It highlights some important considerations concerning resources, keeping up-to-date, and training needs. This work demonstrates that staff may be resistant to asking for assistance or training, and that awareness must be raised as to the skills of information professionals and what they can offer PH professionals with regard to locating and retrieving the best evidence possible. 


\section{Acknowledgements}

The author would like to thank all the staff at the NCCs for their participation in this research. This project was funded by the University of Saskatchewan.

\section{References}

1. Kiefer L, Frank J, Di Ruggiero E, Dobbins M, Manuel D, Gully PR, et al. Fostering evidence-based decision-making in Canada. Can J Public Health. 2005;96(3):1-19.

2. Medlar B, Mowat D, Di Ruggiero E, Frank J. Introducing the National Collaborating Centres for Public Health. Can Med Assoc J. 2006;175(5):493. doi:10.1503/cmaj.060850.

3. Oxford University Press. Public Health. In: Last JM, editor. A Dictionary of Public Health. Oxford: Oxford University Press; 2007.

4. Public Health Agency of Canada. The Federal Strategy: A new approach to public health In Canada. 2004 [cited 15 July 2011]; Available from: http://www.phac-aspc.gc.ca/about_ apropos/federal_strategy-eng.php.

5. Gebbie K, Rosenstock L, Hernandex LM (eds). Who will keep the public healthy? Educating public health professionals for the 21st century. Washington, DC: National Academies Press; 2003.

6. Beahler CC, Sundheim JJ, Trapp NI. Information retrieval in systematic reviews: Challenges in the public health arena. Am J Prev Med. 2000;18(4, Supplement 1):6-10.

7. Rambo N. Information resources for public health practice. J Urban Health. 1998;75(4):807-25. doi:10.1007/BF02344510.

8. Mullet M, Rawding N, Brown CK, Custer D, Suen J. Descriptive epidemiology of local public health systems. Am J Prev Med. 1995;11(6 Suppl):9.

9. Hills RA, Reeder B, Revere D, Lober WB, Abernethy NF. Immunization information and population data sources: the information needs of public health practitioners. Proceedings of the 1st ACM International Health Informatics Symposium; Arlington, Virginia, USA. 1883063: ACM; 2010. p. $459-63$.

10. LaPelle NR, Luckmann R, Simpson EH, Martin ER. Identifying strategies to improve access to credible and relevant information for public health professionals: a qualitative study. BMC Public Health. 2006;6:89. doi:10.1186/ 1471-2458-6-89.

11. Howes F, Doyle J, Jackson N, Waters E. Evidence based public health: The importance of finding difficult to locate public health and health promotion intervention studies for systematic reviews. $J$ Public Health. 2004;26(1):101-4. doi:10.1093/pubmed/fdh119.

12. Lynch $\mathrm{C}$. The retrieval problem for health policy and public health: Knowledge bases and search engines. J Urban Health. 1998;75(4):794-806. doi:10.1007/BF02344509.

13. Chambers LW, Haynes RB, Pickering R, McKibbon A, Walker-Dilks CJ, Panton L, et al. New approaches to addressing information needs in local Public Health agencies. Can J Public Health. 1991;82(2):109-14.
14. Hollander SM, Martin ER. Public health professionals in the Midwest: a profile of connectivity and information technology skills. Bull Med Libr Assoc. 1999;87(3):329.

15. Lee P, Giuse NB, Sathe NA. Benchmarking information needs and use in the Tennessee public health community. J Med Libr Assoc. 2003;91(3):322-36.

16. Rambo N, Dunham P. Information needs and uses of the public health workforce - Washington, 1997-1998. Morbidity and Mortality Weekly Report. 2000;49(6):118-20.

17. O'Carroll PW, Cahn MA, Auston I, Selden CR. Information needs in public health and health policy: Results of recent studies. J Urban Health. 1998;75(4):785-93. doi:10.1007/ BF02344508.

18. Pham M. A mixed-method approach to investigate Ontario public health inspectors' food safety perceptions and information needs. Canada: University of Guelph (Canada); 2010.

19. Gale JA. A profile and training needs assessment of community/public health professionals in Washington State. Northwest Center for Public Health Practice: School of Public Health and Community Medicine, University of Washington1998.

20. Forsetlund L, Björndal A. The potential for research-based information in public health: Identifying unrecognised information needs. BMC Public Health. 2001;1:1-8. doi:10.1186/ $1471-2458-1-1$

21. Forsetlund L, Björndal A. Identifying barriers to the use of research faced by public health physicians in Norway and developing an intervention to reduce them. $J$ Health Serv Res Policy. 2002;7(1):10-8. doi:10.1258/1355819021927629.

22. Robeson P, Dobbins M, DeCorby K, Tirilis D. Facilitating access to pre-processed research evidence in public health. BMC Public Health. 2010;10(1):95. doi:10.1186/1471-245810-95.

23. Revere D, Turner AM, Madhavan A, Rambo N, Bugni PF, Kimball AM, et al. Understanding the information needs of public health practitioners: a literature review to inform design of an interactive digital knowledge management system. J Biomed Inform. 2007;40(4):410-21. doi:10.1016/ j.jbi.2006.12.008

24. Alpi KM. Expert searching in public health. J Med Libr Assoc. 2005;93(1):97-103.

25. Humphreys BL. Meeting information needs in health policy and public health: priorities for the National Library of Medicine and The National Network of Libraries of Medicine. J Urban Health. 1998 Dec;75(4):878-83.

26. Health-Evidence.ca. 2011 [cited 10 July 2011]; Available from: http://phpartners.org/index.html.

27. Partners in Information Access for the Public Health Workforce. 2011 [cited 10 July 2011]; Available from: http:// phpartners.org/index.html.

28. Mullen PD, Ramirez G. The promise and pitfalls of systematic reviews. Annu Rev Public Health. 2006;27:81102. doi:10.1146/annurev.publhealth.27.021405.102239.

29. Armstrong R, Jackson N, Doyle J, Waters E, Howes F. It's in your hands: The value of handsearching in conducting 
systematic reviews of public health interventions. $J$ Public Health. 2005;27(4):388-91. doi:10.1093/pubmed/fdi056.

30. Rambo N, Zenan JS, Alpi KM, Burroughs CM, Cahn MA, Rankin J. Public Health Outreach Forum: lessons learned. Bull Med Libr Assoc. 2001;89(4):403-6.

31. Turner AM, Stavri Z, Revere D, Altamore R. From the ground up: information needs of nurses in a rural public health department in Oregon. J Med Libr Assoc. 2008 Oct;96(4):335-42.

32. Wallis LC. Information-seeking behavior of faculty in one school of public health. J Med Libr Assoc. 2006 Oct;94(4): 442-6, e214-7.

33. National Collaborating Centres for Public Health. About Us. 2009 [cited 2012 Apr 20]; Available from: http://nccph.ca/6/ About_us.ccnsp.

34. Graham ID, Logan J, Harrison MB, Straus SE, Tetroe J, Caswell W, et al. Lost in knowledge translation: Time for a map?. J Contin EducHealth Prof. 2006;26(1):13-24.

35. Davis D, Davis ME, Jadad A, Perrier L, Rath D, Ryan D, et al. The case for knowledge translation: Shortening the journey from evidence to effect. BMJ. 2003;327(7405):33-5. doi:10.1136/bmj.327.7405.33.

36. Canadian Institutes of Health Research. Knowledge Translation Strategy 2004-2009. Ottawa: CIHR2004.

37. Straus SE, Tetroe J, Graham ID. Knowledge translation in health care: Moving from evidence to practice. Chichester, UK: Wiley-Blackwell; 2009.

38. Straus SE, Tetroe J, Graham I. Defining knowledge translation. Can Med Assoc J. 2009 August 4, 2009;181(3-4): 165-8.

39. Mitton C, Adair CE, McKenzie E, Patten SB, Perry BW. Knowledge transfer and exchange: Review and synthesis of the literature. Milbank Q. 2007;85(4):729-68. doi:10.1111/j. 1468-0009.2007.00506.x.
40. Roth DZ, Henry B. Social distancing as a prevention measure. Winnipeg: National Collaborating Centre for Infectious Diseases. 2011.

41. British Columbia Lung Association, British Columbia Centre for Disease Control, National Collaborating Centre for Environmental Health. Radon: Threats, challenges \& actions. 2012 [cited 2012 Apr 26]; Available from: http://www.ncceh. ca/en/professional_development/ncceh_workshops/radon.

42. National Collaborating Centre for Aboriginal Health. The importance of disaggregated data. Prince George: NCCAH. 2010.

43. Grefsheim SF, Rankin JA. Information needs and information seeking in a biomedical research setting: a study of scientists and science administrators. J Med Libr Assoc. 2007 Oct;95(4):426-34.

44. Cogdill KW. The information needs and information seeking of nurses [Doctoral dissertation]: The University of North Carolina at Chapel Hill; 1998.

45. Banks MA, Cogdill KW, Selden CR, Cahn MA. Complementary competencies: public health and health sciences librarianship. J Med Libr Assoc. 2005 Jul;93(3):338-47.

46. Finkle-Perazzo D, Jetha N. Online resources to enhance decision-making in public health - Cross-Canada Forum. Chronic Diseases and Injuries in Canada. 2011;31(4):172-5.

47. Bostick SL. The development and validation of the library anxiety scale [Doctoral Dissertation]: Wayne State University; 1992.

48. Cleveland A. Library anxiety: a decade of empirical research. Libr Rev. 2004;53(3):177-85. doi:10.1108/00242530410526583.

49. Mellon CA. Library anxiety: A grounded theory and its development. College \& Research Libraries. 1986;47(2):160-5.

50. Onwuegbuzie AJ, Jiao QG, Bostick SL. Library anxiety: Theory, research, and applications: Scarecrow Pr; 2004. 